\title{
Saúde do trabalhador e o desafio ambiental: contribuições do enfoque ecossocial, da ecologia política e do movimento pela justiça ambiental
}

\author{
Workers' health and the envi ronmental challenge: \\ contributions from the ecosocial approach, the political \\ ecology and the moviment for environmental justice
}

1 Cen tro de Estu dos de Saúde do Trabalhadbr e Ecologia Humana, Escola Nacional de Saúde Pública Sérgio Arouca, Fiocruz. Av. Leopoldo Bulhões 1.480, Manguinhos, 21041-210, Rio de Ja neiro RJ. marcelo.firpo@ensp. fiocruz.br
Abstract This article links the workers' health and the environmental issue, using as references the ecosocial approach, the political ecology and the movement for environmental justice. Each reference detaches a specific dimension: (1) the ecosocial approach emphasizes the dimension of knowled ge through the devel opment of in tegra ted assessment and the new role of science in ord er to surpass simplistic ideologies based on positivism and fragmentation, which ignore the complexity of socio-environmental problems and their uncertainties; (2) the political ecology and the con cept of environmental justice discuss the dimension of power, in which socio-environmental problems a re unders tood as consequences of cen ter-peripheries relationships of domination that despair the need of human beings and nature; and finally (3) the movement for environmental justice presents the dimension of action, which is propitia ted the consciousness that many socio-environmental problems have their origin in an unfair devel opment model, specially for the most discriminated and poor population. Here we discuss the role developed by the Brazilian Network of Environmental Justice, which can be se en as a stra tegic example how to face environmental challenges in Latin-American countries as Brazil.

Key word s Worker's health, Ecosocial approach, Environmental justice, Political ecology, Environmental health
Resumo Este artigo relaciona o campo da saúde do tra balhador à temática ambiental, tendo por referências o en foque ecossocial, a ecolo gia politica e o movimento pela justiça ambiental, cada qual destacando uma dimensão específica: (1) no en foque ecossocial destacamos a dimensão do conhecimento, com ênfase no desenvolvimento de análises integradas e na análise do pa pel da ciência e sua necessária renovação, sem a qual a luta política pode recair em ideologias simplistas baseadas em ciências positivistas e fragmentadas, as quais ignoram a co $m$ pl exidade dos probl emas socioambientais e suas incertezas; (2) na abordagem da ecologia politica e no conceito de justiça ambiental enfatizamos a dimensão do poder a partir da (re) produção das relações de dominação cen tro-periferias marcadas pelo despre zo sobre as pessoas e a natureza; e finalmente (3) no movimento pela justiça ambiental realçamos a dimensão da ação gerada pela consciência que inúmeros problemas ambientais possuem sua origem em um modelo de desenvolvimen to injusto, particularmente para com as populações mais pobres e discriminadas. Nesse tópico destacamos a experiência da Rede Brasileira de Justiça Ambiental como um exemplo estratégico para o enfrentamento de problemas socioambiental em países latino-americanos como o Brasil.

Palavras-chave Saúde do trabalhador, Ecossocial, Justiça ambiental, Ecologia política, Saúde ambiental 


\section{Introdução: \\ saúde dos trabalhadores e o necessário re sgate da questão ambiental}

A questão apresentada para a 3a Conferência Nacional de Saúde dos Trabalhadores pelo segundo eixo temático-como incorporar a saúde dos(as) trabalhadores(as) nas politicas de desenvolvimento sustentável do País - aborda um tema recorrente que remonta ao próprio surgimento da área de saúde do trabalhador nos anos 80 , mas que permanece pouco aprofund ado pelo campo da Sa ú de Coletiva.

De acordo com Mi n ayo et al. (1999), a saúde pública bra silei rapos sui atualmen te três paradigmas básicos que são adotados para compreender a interface entre saúde e ambiente: (1) o biomédico, originado na parasitologia clássica; (2) outro oriundo do saneamento clássico e que aborda a temática ambiental a partir da engenharia ambiental; e finalmente (3) o da medicina social, com origens nos anos 70 e que marca o surgimen to da saúde coletiva no país. Es te último paradigma aborda probl emas de saúde das populações a partir das dimensões política, econômica e cultural, mas somen te a partir dos anos 90 iniciou-se uma produção acadêmica mais sistemática sobre a relação saúde e ambiente no âmbito da saúde coletiva (Leal et al., 1992a, 1992b; Ta mbellini \& Câmara, 1998; Porto, 1998; Min ayo et al. , 1999; Freitas, 2003). Até então a temática na saúde pública brasileira permanecia restrita aos dois primei ros paradigmas mencionados e às abordagens mais técnicas da saúde ambiental marc adas por disciplinas como a epidemiologia e a toxicologia ambiental.

Em 1986 foi publicado no Brasil o livro da italiana Laura Con ti den om in ado Ecol ogia, capital, tra balho e ambien te (Conti, 1986). Um ano an tes havia sido inaugurado o Cen tro de Estudos da Saúde do Trabalhabr e Ecologia Humana (CESTEH), da Fundação Oswaldo Cruz, um dos centros de pós-graduação que surgi ram no âmbito da Saúde Coletiva no país para formar profissionais e sedimentar academicamente as ex periências de saúde do trabalh ador em curso. O livro de Con ti e a criação do CESTEH apontavam, já no seu início, para uma pers pectiva de que a área de saúde do trab alh ador aprofundasse e integrasse, em termos con cei tuais e operacionais, as discussões e políticas envolvendo probl emas de saúde, trabalho e ambi ente.

Nessa época a crise ambi ental ga nhava contornos políticose con ceituais mais importantes com a publicação pela ONU do ch a m ado Relatório Bruntland, em homenagem à primeiraministra norueguesa que, nos anos 90, viria a se tornar diretora da Organização Mundial da Saúde. Esse relatório introduziu o con cei to de desenvolvimento sustentável no debate ambi ental e precedeu a Eco-92, quando representantes de inúmeros países se reuniram no Rio de Janeiro e assumiram os com promissos que constam da Agenda 21, uma espécie de acordo global dos países para reverterem a alarmante tendência de degradação ambi ental apontada por especialistas e ativistas ecológicos.

A crise ambiental contem porânea vem intensificando as discussões e a percepção pública acerca dos efei tos dos processos de produção e con sumo das socied ades industriais modernas sobre a saúde humana e a dos ecossistemas. Dentre outros fatores, podemos destacar a degradação ambiental em várias regiões do planeta e o reconhecimento científicodos ri s cos ecológicos globais, tais como o chamado efei to estufa, a redução da camada de ozônio, a destru ição de florestas e da biod iversidade, a poluição atmosférica e marítima (Corvalán et al., 1996). Os ris cos ambientais vêm fazendo com que as escalas espaciais e tem porais para as análises dos riscos modernos torn em-se cada vez mais amplas e complexas, ao mesmo tempo em que in tensificaram os impera tivos éti cos relacionados à ameaça da continuidade da vida no planeta, colocados anteriormente com a ameaça da guerra nuclear total (Porto, 2004a).

Apesar do agravamen to de diversos problemas ambientais no país e no planeta, os anos 90 não viram no Brasil uma aproximação concei tual ou político-institucional entre as áreas de saúde do trabalhador e saúde ambiental. Não obstante os problemas políticos e financei ros que constran geram o SUS e o conjun to das políticas sociais, numa década marc ada pela globalização e implementação da agenda neoliberal, uma série de indicadores aponta para uma razoável expansão do número de profissionais e instituições vinculadas às áreas de saúde do trabalhador e po steri ormente à saúde ambiental, sendo esta impulsionada pela criação do setor de Vi gilância Am bi ental no âmbito do proj etoVIGISUS. Esse crescimento, contudo, vem ocorren do de forma paralela e pouco integrada.

Em termos acadêmicos, ao lon go da décad a de 1990 alguns artigos em revistas nacionais buscaram analisar de forma integrada questões de saúde, trabalho e ambiente (Tambellini \& 
Câmara, 1998; Augu s to et al. , 1998; Porto \& Almeida, 2002). Tais arti gos repre sentam a visão de alguns autores que se preocupam em articular as dimensões trabalho-ambien te ou produção-ambiente, mas não indicam uma tendência dara de aproximação conceitual e política entre as áreas de saúde do trabalhador e a ambi ental no campo da saúde pública brasileira.

Não é intenção deste artigo aprofundar a análise dos motivos para o que pareceu ser, pelo menos até o momen to, um caminhar paralelo dessas duas áreas. Antes, o obj etivo principal do artigo é apontar alguns referenciais que possam facilitar a discussão integrada de questões de saúde, trabalho e ambi en te na atualidade, sob uma pers pectiva da saúde coletiva.

São três os referenciais a serem trabalhados neste artigo: (1) o de s envo lvi men to de abordagens ecossociais no campo da saúde pública/coletiva; (2) as discussões provenientes da ecologia política e da justiça ambiental; (3) finalmente e de caráter mais pragmático, a con strução e atuação da Rede Brasileira de Justiça Ambiental. Embora os referenciais e questões selecionados para este artigo ainda possuam penetração limitada nos periódicos da Saúde Pública intern acional e na Sa ú de Col etiva brasileira, eles podem con tri buir para a superação dos paradigmas médico-assistencialista e sanitário ainda hegemônicos no SUS e na saúde pública do país. Esta necessidade vêm sendo apontada nos últimos anos principalmente a partir dos avanços conceituais e operacionais das propostas sobre vigilância da saúde e promoção da saúde (Tei xeira et al., 1998; Paim \& Al m eida Filho, 2000; Czeresnia e Freitas, 2003).

Ao apresentar e aprofundar os referenciais selecionados destacamos, em cada um deles, uma dimensão importante que nos ajudam a com preen der e enfrentar os desafios referentes aos problemas socioambi entais contemporâneos:

(1) no enfoque ecossocial de stacamos a dimensão do conhecimento, voltada para o entendimen to da complexidade e das incertezas, bem como para o de senvo lvi m en to de abord agens integradas que superem os limites de um modelo de ciência cujos paradigmas restritos fragmentam os fenômenos relacionados aos mundos das coisas inanimadas, da vida biológica e dos seres humanos;

(2) na ecologia polí tica e na ju stiça ambi ental realçamos a dimensão do poder. Aqui os probl emas ambientais (e os de saúde deles decorren tes) são en ten di dos a partir daexistência de relações cen tro - peri feria nos territórios, cuja origem se encontra em formas de dominação, in tervenção e con trole sobre o uso dos recursos realizadas por parte de certos agentes (investidores econômicos e governos). A divisão cen tro - peri feria que produz probl emas socioambientais está fundada num sistemático desrespeito à natureza e aos interesses legítimos dos habi t a n tes do lugar - comunidades de moradores e trabalhadores -, empurrando-os para as peri ferias política, econômica e geográfica e jogando sobre seus ombros a parte mais "suja" do desenvolvimento, ou seja, as principais cargas ambientais;

(3) finalmen te enfatizamos a dimensão da ação ten do por exemplo concreto a con strução da Rede Brasileirade Ju s tiça Ambiental, con siderada uma importan teestratégia social e política de enfrentamento dos probl emas socioa mbientais em países latino-americanos como o Brasil. Um elemento central que conecta os membros desta rede é a compreensão de que inúmeros problemas ambientais originam-se num modelo de desenvo lvimen to injus to que joga sobre os om bros das populações mais pobres e discriminadas as principais cargas ambientais, sendo tais injustiças enfrentadas por redes sociais que se baseiam em valores como a solidaried ade e o res pei to simultâneo à natureza e aos direi tos humanos.

Conforme indica o espanhol Joan Martinez-Alier, o movim ento pela ju s tiça ambiental - ou, como ele também intitula, a mbi entalismo popular ou dos pobres - vem se colocando como alternativa crítica às duas outras correntes hegemônicas no interior do movimen to ambi entalista internacional:

(1) a primeira, de caráter con servacionista, é marcada por uma visão preservacionista e romântica da natureza, a qual despreza a dimensão humana e social da questão ambiental, focando sua preocupação exclusivamente na preservação das florestas, da biodiversidade e dos animais em extinção;

(2) a outra é chamada pelo autor de evangelho da eco-eficiência, por priorizar a internalização de custos e práticas gerenciais ambientais "limpas" à lógica do de s envo lvimento capitalista, colocando nas mãos das instituições, especialistas e tecnoburocracias a re s pon sabilidade pela implem entação dos critérios e políticas que con duzirão ao "de s envolvim en to su sten tável". Es te con cei to acabou tornando-se excessivamente genérico, e tem servido ideologicamen te para favorecer os interesses economicis- 
tas e obscurecer as contradiçõoes na discussão dos problemas socioambientais. E é por isso que muitos movimen tos sociais têm preferido outras expressões, como sustentabilidade socioambiental, que enfatiza a idéia de o desenvolvimen to ser um processo em construção e que precisa necessariamen te integrar dimensões ambi entais e sociais.

O autor acredita que os referenciais selecionados podem contribuir para o desenvolvimento de estratégias políticas e operacionais que revertam as tendências degradantes dos modelos hegemônicos de desenvolvimento econômico e tecnológiconos atuais tempos de globalização. Ao mesmo tempo eles permitem o avançar na con s trução de agendas de discussão comuns en tre ambas as áreas da saúde ambi ental e do trabalhador, em articulação com o campo ambiental, com diversos movimentos sociais, ONG's, instituições e entidades que vêm trabalhando conjuntamente na forma de redes sociais.

\section{A dimensão do conhecimento: rumo a uma abordagem ecossocial}

Recen tem en te alguns autores da saúde pública vêm se destacando na discussão sobre a integração de abordagens ecossistêmicas e sociais no en tendimento de problemas de saúde da população. Em um artigo de referência sobre o tema, Levins \& Lopez (1999) fazem isso tendo como ponto de partida a discussão acerca dos paradoxos do sistema de saúde pública dos EUA, o qual gasta bem mais que outros países e se encontra entre os piores do mundo industrializado em termos de indicadores de saúde. Os investim en tos cen tram-se num modelo médico - as sis tencialista caro, iníquo eineficaz, sem atuar mais efetivamente nos modos de vida e nos ambien tes que afetam a saúde das populações. Um modelo altern a tivo na análise de problemas de saúde de caráter preventivo, denominado pelos autores de eco ssocial, deveria incorporar uma visão mais holística acerca das complexidades que caracterizam a saúde no nível das populações, ten do por referência movimentos e correntes intelectuais como a saúde de ecossistemas, a justiça ambiental, a determin ação social e a saúde para todos.

Não é som en te o agravamento da crise ecoló gica que vem produ zin do um maior intere sse por questões teórico-metodológicas voltadas para a compreensão da complexidade e ao de- senvolvimen to de análises integradas no enfrentamento de problemas de saúde. As doenças transmissíveis, cujo su cesso no seu en frentamento marcou a ampla institucionalização da saúde pública como um dos pilares das socie$\mathrm{d}$ ades modernas, também vêm colocan do novos desafios. Alguns exemplos recentes são o recrudescimen to de diversas doenças endêmicas em áreas onde já se encontravam controladas; o surgimen to de novos probl emas como a Aids e a hepatite C; e o aumento da resistência de muitos agen tes infecciosos aos antibió ti cos (Sabroza e Waltner-Toews, 2001). Tais fatos, além da persistência das desigualdades socioeconômicas em várias regiões, contribu em para romper com a idéia de que a transição epidemiológica passagem de um quad ro de morbi mortalidade marcado pelas doenças do "atraso" e da "pobreza” para doenças típicas das socied ades modernas - ocorreria linearm en te através da su peração do "subdesenvo lvimen to" soci oeconô mico e da modernização institu cional e técnico-científica das sociedades (Possas, 2001).

Um aspecto básico da abordagem ecossocial proposta por Levins \& Lopez (1999) estaria no reconhecimento dos níveis e características que marcam a complexidade dos problemas de saúde das populações. Quanto maiores forem as fron teiras dos sistemas socioambientais analisados, maiores serão as escalas espaciais e tem porais envo lvidas, implicandoincertezas e dificuldades a serem su peradas, ou pelo menos explicitadas, por análises integradas. $\mathrm{Pa}$ ra tanto, é nece s s á rio superar as dico tomias que caracterizam as ciências atuais no campo da saúde, através de uma com preensão da natureza sistêmica dos problemas de saúde e do respei to às dinâmicas dos ecossistemas. Uma das tarefas no desenvolvimen to de abord a gens eco ssociais é a de reeducar nossas percepções e intuições em torno da compreensão de realidades complexas, fazen do com que con cei tos provenien tes da teoria de sistemas e da ecologia evolucionária - como retroalimentação (feedback), conectividade e transições de fase - sejam tão familiares quanto os con cei tos e métodos estatísticos trad i ci onais - como a regressão linear - o são para as ciências positivistas.

Também Krieger (2001), em seu artigo de revisão, caminha na mesma direção dos autores anteriores ao apontar a importância da pers pectiva ecossocial para a epi demiologia social melhor com preender os problemas atuais da saúde das populações. O objetivo dessa pers pectiva não é o de ser uma teoria totalizan- 
te para explicar tu do-e con s eqü en tem en te nada -, mas sim produzir um con jun tode princípios integrais, e, na medida do possível, empiricamente verificáveis, que orien tem a investigação e as ações práticas, in clusive no reconhecim en to de suas incertezas e limitações. Isso se torna mais relevante atualmen te diante das promessas da moderna biotecnologia, impulsion ada pelos avanços recen tes da biologia molecular. A nova onda dos OGM's e das terapias gen éticas ren ovam as tensões en tre paradigmas e interesses nas discussões públicas sobre os fatores que mais influenciam a saúde, como a carga genética, o comportamen to indivi dual e as condições sociais, de trabalho e ambientais. A biotecnologia, movida pelos interesses econômicos de curto prazo através de programas de $\mathrm{P} \& \mathrm{D}$ das gra $\mathrm{n}$ des corporações em torno das aplicações da genética, vem ren ovan do o paradigma médico-assistencialista e a ideologia do o timismo tecnológi co (Strand, 2001), cujo caráter reducionista, despolitizador e individualista precisa ser enfrentado pelo desenvolvimen to de en foques eco s s ociais que ava n cem na integração de dimensões sociais ebiológicas.

Um dos pilares para uma visão ecossocial dos problemas de saúde encon tra-se no desenvo lvimento da chamada abord a gem ecossistêmica em saúde. No Brasil esta abordagem foi coloc ada recentem en te pelo artigo do canadense Waltn er-Toews (2001). Pa ra o autor, é nece ssário serem superados os modelos causais mais lineares usados por epidemiologistas e pesquis adores do campo biomédico paut ados na coleta pos-facto de doenças e mortes. A questão ecoló gica e discussões sobre promoção da saúde reforçam a idéia que a saúde é muito mais que a ausência de doenças, e que muitas medidas isoladas de redução de doenças podem gerar efei tos contrá rios aos esperados. Pa ra tanto, uma abord a gem ecossistêmica em saúde passaria pela combinação de vários insights provenien tes da ecologia, das teorias sobre sistemas complexos, do de s envo lvim en to de análises integradas e metodologias participativas, dentre o utras perspectivas teórico-metodológicas que vêm assumindo um papel de relevância no campoambi en tal. Elas forn eceriam as bases intel ectuais e metodológicas para a construção de processos sociais e decisórios que possibilitem soluções adaptativas criativas de problemas dentro de uma perspectiva participativa e democrática.

Compreender problemas de saúde a partir de um en foque ecossocial é fundamental para que propostas de desenvolvimen to econô mico e tecnológico possam resultar em balanços mais positivos entre os ben efícios e os prejuízos dele decorrentes. Especialmente para o campo da saúde pública tal desafio é estratégico para desenvolver e implementar ações de promoção da saúde. Dessa forma a saúde pública poderia melhor considerar as interações que con ti nuam a ser ign oradas em várias visões e políticas de saúde orientadas pelo paradigma biomédico ou por uma visão ecológica reducionista. Podemos, resumidamente, citar alguns exemplos de como visões reducionistas podem gerar intervenções problemáticas.

- Uma área rural relativamen te conservada, ao ser modificada pela expansão agrícola, pela construção de vias de transporte ou pelo cre scimen to de áreas urbanas, pode ter reduzidoo número de predadores naturais de roedores e insetos transmissores de certas doenças, ocasionando a emergência de surtos epidêmicos ouendêmicos.

- Por sua vez, medidas de controle de endemias podem con tribuir para a contaminação e exposição de áreas e populações atingidas pelos inseticidas tóxicos, inclusive os trabalhadores re s pon sá veis por sua aplicação.

- A difusão e o abuso no uso de antibióticos podem, no médio pra zo, fort a l ecer a resistência de vários microor ganismos que originalmente pretendiam comb a ter.

- Medidas de con forto ambi ental em climas tanto quentes quan to frios podem favorecer o surgimento da chamada síndrome do edifício doente, que afeta a saúde das pessoas que nele circulam por meio de contaminação química e microbiológicas da atmosfera.

Os exemplos anteriores realçam uma dimensão fundamental abordada pelo enfoque ecossocial: a do conhecimento, a qual se de s dobra na necessidade de su perarmos o atual modelo hegemônico de se fazer ciência. Como observou Bruno Latour em sua metáfora (apud Fun towicz e Ravetz, 1993), o lugar da ciência moderna pode ser imaginado através dos trabalhos pioneiros de Pasteur na saúde pública, com a con quista e domes ticação de uma natureza ameaçadora pelo mun do do laboratório científico. Mas a crise ecológica con tempor ânea vem fazendo com que haja uma inversão: a gora é a natureza que "rei nvade" o mun do do laboratório, com riscos globais em alcance e complexos em sua estrutura, escancaran do os limites da ciência e instituições modernas de com preendê-los e controlá-los. 
Para Funtowicz e Ravetz (1997), o modelo hegemônico de ciência tem sua ori gem na análise de fenômenos fisicalistas do mundo inanimado, que com seus modelos preditivos quantitativos relativamente precisos tanto sucesso produziram no de senvo lvim en to das en genharias, tecnologias e produtos que fazem parte da vida moderna. Con tu do, tanto a complexidade ordinária do mun do da vida biológica quanto a complexidade emergente ou reflexiva do mundo do humano ten dem a ser menosprezadas por um modelo de ciência normal, no sentido dado por Kuhn (1987), o qual separa as várias disciplinas científicas por parad i gmas rígi dos que recortam excessivam en te a realidade e não se comunicam en tre si.

Como no verso de Fernando Pessoa - Navegar épreciso / Viver não é preciso - ou ainda de o utro poeta que viveu no século 14 , o italiano Petrarcha, que escreveu A navegação é uma ciência exata, em compa ração com a vida, que sabemos onde começa e jamais onde termina, o drama da ciência moderna continua sendo o de enfrentar a complexidade e os mistérios do viver, fornecendo sentido às ações humanas. Mas a resolução dada pela ciência normal a este drama tem sido negar boa parte da complexidade através de sua crescen te especialização, afirmando mais suas certezas através da pretensa precisão de números gerados por modelos quantitativos complicados, e não reconhecen do ou mesmo ocultando suas incertezas e ignorâncias.

Muitos dos probl emas socioambientais relevan tes da atualidade tra zem à tona os limites da ciência normal, pois possu em um elevado nível de complexidade, alto grau de incertezas e disputa de valores, ao mesmo tempo em que n ecessitam tom adas de decisões emergenciais. Nesses casos, as abordagens escolhidas para analisar tais problemas precisam incorporar seus aspectos essenciais, os quais envolvem múltiplas dimensões e são tanto quantitativos quanto qualitativos. Aqui o crit tério dequalidade na produção de conhecimen to deve passar pela construção de abordagens integradoras e con textualizadas, que propiciem o diálogo entre as diversas áreas de conhecimento e destas com o públ ico, ao mesmo tem po em que reconheçam e explicitem as incertezas e os valores em jogo. Uma ciência ética e transdisciplinar, denominada por Fun owicz \& Ravetz (1994, 1997) de ciência pós-normal a qual reconheça e en fren te a complexidade, e também promova a participação legítima de todos os envolvidos através de uma comunidade ampliada de pares.

\section{A dimensão do poder: a visão terri torialista da ecologia política e da justiça ambiental}

O que existe em comum en tre uma comunidade indígena que está sen do afet ada na Amazônia pela con strução de barra gens hidrelétricas e os moradores de um conjun to habitacional popular em São Paulo, con struído em cima de uma área on de durante décadas resíduos industriais perigosos foram enterrados sem o men or cuidado? Ou então en tre os trabalhadbres ex trativistas que convivem e depen dem dos f rutos da natureza, mas são afet ados em sua sobrevivência e integridade por grileiros, madeireiras e o agronegócio, com os trabalhadores que adoecem e morrem em função da exposição a substâncias perigosas como o amianto e os POP's (poluentes orgânicos persistentes)? Ou ainda entre indígenas, pequ enos agricul tores e quilombolas, que têm sua saúde, cultura e subsistência ameaçadas pela expansão da monocultura do eucalipto para a produção de celulose ou siderúrgicas, e moradores das periferias urbanas em áreas de ris co sem saneamen to próximas a fábricas poluentes - as “zonas de sacrifício" que as populações pobres são forçadas a morar?

A resposta é que todas essas populações são vítimas de um modelo de desenvolvimen to marcado pela injustiça ambiental, is toé, grandes inves timentos e negócios realizados que se a propriam dos recursos existen tes nos territórios e con centram renda e poder, ao mesmo tempo em que atingem a saúde e integridade dos trabalhadores, dos seus habitantes e dos ecossistemas. Os lucros e benefícios são concentrados nas mãos de poucos, enquanto as cargas do de senvo lvimento são distri buídas aos trabalhadores, às populações pobres e discriminadas, como pobres, n egros, índios emulheres. Num modelo de desenvolvimento injusto são estes grupos vulnerá veis, freqüentemen te invisíveis nas discussões públicas e sem voz nas decisões que lhes dizem respeito, os que mais recebem os efei tos da poluição, da con centração urbana e da falta de investim en tos em políticas públicas, como educação, saneamen to, saúde e meio ambiente. Nesses con textos, problemas de saúde e ambiente podem ser vistos como questões de (in)justiça ambi ental (Acselrad, Herculano e Pádu a, 2004).

A Ecologia Política tem servido como importante base teórica para o movimen to da justiça ambiental ao en xergar como pano de 
fundo da atual crise social e ecológica a formação de hiera rquias centralizadas de poder que se sustentam a partir de recursos não-locais, distanciados dos territórios onde vivem a maioria das comunidades e os ecossistemas que sofrem com os principais problemas decorren tes desta divisão. A Ecologia Política e o movimento pela justiça ambiental repensam questões sociais, econômicas e ambientais numa pers pectiva terri torialista, e têm por desafio bá s i co fort a l ecer a integridade e a saúde das comunidades - incluindo os trabalhadores/as - e dos ecossistemas (M'Gonigle, 1999). Nessa visão, portanto, podemos en ten der os ambientes de trabalho e as fábricas no interi or de um território mais amplo e de um modelo de desenvolvimento que os conformam, incluindo a produção e distribuição dos riscos ambi entais e ocupacionais sobre os ombros das populações mais vulneráveis.

A Ecologia Política realiza a crítica dos fundamentos filosóficos da econ omia neodássica através de questões como os conflitos distributivos e a incom ensurabilidade dos valores ambientais, ao mesmo tem po em que busca avançar sobre a econ omia política de tradição marxista ao incorporar questões ecológicas no enten dim en to das dinâmicas econômicas e de poder que caracterizam as sociedades modernas (Martinez-Alier, 2002; O’ Connor, 1994). A dialética entre centro e periferia nos territórios e as tendências históricas para a centralização s ocial e a hiera rquia institucional são repensadas à luz da sustentabilidade (Mc'Noogle, 1996). Esta dialética cen tro - peri feria se refere à existência de con centração de poder políti co e econômico, e por con s eqüência à discrepância en tre os que se ben eficiam e os que recebem as cargas negativas do de senvo lvimento econô $\mathrm{mi}$ co. Tal dialética pode ser percebida, de um lado, no espaço político-institucional por meio de processos decisórios que ten dem a excluir a participação e os interesses dos afetados pelas decisões; de outro lado, no espaço geográfico a través da con formação nos territó rios de áreas ricas e "salubres" isoladas daqu elas pobres, sem infra-estrutura básica de serviços, perigosas e insalubres.

A Ecologia Política fornece importantes elemen tos conceituais para a discussão sobre quem, quando e como se ganha ou se perde saúde em decorrência de certos investimentos realizados nos territórios. A con tradição central do desenvolvim en to econômico e tecnológico resideno fato de que o "progresso" técnico e econômico pode não significar progresso humano. A ri queza de um pode significar a doença e a morte do outro, o progresso do agora pode representar o constrangimento do futu ro, a expansão urbana e industrial pode implicar a degradação de ecossistemas, extinção de espécies, o fim de recursos naturais e a contaminação do ar, água e alimentos.

Uma ecologia política propicia en ten der os ris cos ambientais a partir das dinâmicas de poder envolvidas na dialética en tre cen tro e periferia e as tendências históricas que propiciam ou revertam tendências de cen tralização social e hierarquização institucional, as quais estão na base das vulnerabilidades das populações mais expostas. Significa também propor e implem entar estratégias de ação que reconfigurem as relações de poder em direção a socied ades mais justas, democráticas e ecologicamente sustentá veis. É nesse sen tido que devemos en ten der a importância das metodologias participativas, da democratização dos processos decisórios e do movim en topela justiça ambi en tal.

\section{A dimensão da ação: o movimento pela justiça ambiental e a Rede Brasileira de Justiça Ambiental}

O movimen to pela jus tiça ambi ental (JA) propõe articular o movimen to ambientalista desenvo lvi do nas últimas décadas com a luta contra dinâmicas discriminatórias que colocam sobre o ombro de determinados grupos populacionais os malefícios do desenvo lvimen to econômico e industrial. Ele vem se constituindo num importante exemplo de resistência aos efei tos nefa s tos de um capitalismo globalizad, o qual utiliza sua cre s cen te liberd ade locacional de investimentos entre regiões e planetas para inibir a con strução de parâmetros sociais, ambientais, sanitários e culturais direcionadores do desenvolvimento econômico e tecnológico.

Sua ori gem está rel acion ada ao movimen to contra a discriminação racial e étnica presen te nos movimentos pelos direi tos civis da socied ade norte-americana nos anos 70, e que na década seguinte passou a incorporar dimensões de dasse, gênero e outras formas de discriminação social (Bullard, 1994; Porto, 2004b). A carta de princípios para a ju s tiça ambi ental apresentada nos EUA em 1991 fala da necessidade de serem reinvertidas as lógicas de colonização e opressão política, econômica e cultu ral que marc a ram os cincos séculos de colonização no continente. 
No Brasil e na América Latina o movimento pela JA é rela tivamente recen te, e po s sui como importante marco a criação da Rede Brasileira de Justiça Ambiental (RBJA). Ela é uma articulação form ada por representantes de vários movimen tos sociais, Ong's, entidades ambientalistas, sindicatos, pesquisadores, organizações afrodescen den tes e indígenas de todo o Brasil. A rede foi criada logo após a realização do Coló quio In ternacional sobre Justiça, Trabalho e Gidadania, realizado em Niterói entre 24 a 27 de setembro de 2001, organizado por uma iniciativa conjunta de várias entidades (Fase, UFF, UFRJ, Fiocruz e CUT). O colóquio reuniu cerca de 120 pessoas, in cluindo convid ados dos EUA, Chile e Unuguai, e seu principal re sult adopode ser visualizado no Man ife sto de Lançamen to da rede Brasilei ra de Ju s tiça Ambiental, construído coletivamen te por vários movimentos sociais e apresentado publicamen te no Fórum Social Mundial de Porto Al egre em 2002. A versão integral de ste doc u m ento, bem como um amplo conju n to de inform ações sobre a RBJA podem ser encon trados no portal da Rede (www.justicaambiental.org.br).

Esse documento define o con cei to de inju stiça ambi ental como o mecanismo pelo qual soci edades desiguais, do po n to de vista econômico e social, destinam a maior carga dos danos ambientais do desenvolvimento às populações de baixa renda, aos grupos sociais discriminados, aos povos étnicos tradicionais, aos bairros oper ários, às populações marginalizadas e vulner á vei s. Já o con cei to de justiça ambiental é en ten dido por um conjunto de princípios e práticas que asseguram que nenhum grupo social, seja ele étnico, racial, de classe ou gênero, supo rte uma parcela despropo rcional das conseqüências ambi entais nega tivas de operaçõeseconômicas, decisões de políticas e de programas federais, estaduais, locais, assim como da ausência ou omissão de tais politicas, assegurando assim tanto o acesso jus to e eqüitativo aos recursos ambientais do país, quanto o acesso amplo às inform ações rel evantes que lhes dizem res pei to e favorecen do a con s ti tuição de movim en tos e sujeitos coletivos na construção de modelos alternativos e dem ocráticos de de senvo lvimento.

A principal função da RBJA tem sido a de articular diferentes movimen tos sociais que a tuam com questões de ju s tiça ambiental, mesmo que até então a maioria deles não incorporasse tal expressão. Apesar de ter surgi do nos EUA, o movim en to pela justiça ambi ental possui um en orme po tencial político por possibili- tar a aproximação en tre as reivindicações por justiça social e o cuidado ambi ental em países da América Latina. Como revela o historiador ambiental Pádua (2002), as raízes coloniais e esc ravistas impregnaram profundamentea socie$\mathrm{d}$ ade brasileira (e latino-americana), estabelecen do uma perversa combinação en tre de s tru ição da natu reza e exploração do trabalho humano. Rom per este ciclo é fundamental para que alcancemos um novo estágio civilizatório.

A RBJA po s sui como principais obj etivos:

- Promover o intercâmbio e troca de experiências, refl exões teóricas, análises de con texto e elaboração de estrat égias de ação en tre múltiplos atores de lutas ambientais, inclusive através de assessorias aos grupos atingidos por parte de profissionais da área ambiental, social e de saúde que atuam na Rede;

- Aproximar pesquisadores e ativistas sociais brasileiros, en corajan do-os a form a rem parcerias para o trabalho conjunto;

- Criar agendas nacionais e regi onais de pesquisa e ação com vistas a enfrentar casos concretos de injustiça ambiental e elaborar propostas políticas e demandas endereçadas ao poder público;

- Articular o campo dos direitos humanos com con fli tos socioambi entais decorren tes dos novos ciclos de investimen to econômico e a propriação privada dos recu rsos naturais que produ zem exclusão e ex propriação.

A RBJA vem mobilizando inúmeras entidades, movimen tos sociais e ambientalistas no enfrentamento aos avanços dos investimentos produtivos potencialmente degrad a n tes em vários territó rios e locais de trabalho. Den tre outros investimentos, vêm ten do destaque: a exploração e produção de petróleo; a mineração; a con strução de barragens hidrelétricas; os setores econômicos que produzem e utilizam substâncias químicas extremamen te perigosas como o amianto e os POP's; a expansão de monoculturas intensivas como a soja e a plantação de eucaliptos. A Rede vem funcion a n do principalmente através de uma lista de discussão organizada por uma animadora da Ong Fase, e inúmeras atividades vêm sendo desenvo lvidas nos últimos anos, inclu sive oficinas no interi or do Fórum Social Mundial, grupos de trabalho, en contros, seminários e mobilizações.

Um exemplo con c reto que ilustra o po tencial da Rede foi a recen te mobilização realizada no ano de 2004 que bloqueou a transferência para a Bahia do lixo tóxico produ zi do pela empresa Rhodia na Baixada Santista, o qual seria 
incinerado no Pólo Industrial de Camaçari. A mobilização inicial da entidade ACPO (Associação Contra os Polu en tes Orgânicos), formada por ex-trabalhadores da Rhodia, revela como a atuação solidária em forma de redes constitui-se numa estratégia importante para im pedir a ex portação de ri s cos en tre regiões de um mesmo país ou en tre países.

\section{Con clusão: saú de coletiva e a integração de questões de saúde, trabalho e ambien te}

Por todos os el em en tos apresentados ao longo de s te tex to, a tem á tica ambi ental pode ser consi derada um desafio civilizatório incon testável, o qual vem se integra n do mais e mais à agenda política de todas as nações. Especialmente para o campo da saúde do trabalhador, o qual trata de condições e ambien tes de trabalho que fazem parte e intera gem com ambi en tes mais gerais e ecossistemas, não podemos menosprezar a importância da questão ambiental para o futu ro da humanidade como um todo, tampou co polarizá-la com questões e demandas específicas dos movimen tos de trabalhadores. Experiências passadas e atuais revelam como a (falsa) polarização entre defesa da saúde e do emprego podem inviabilizar ações mais efetivas de saúde do trabalhador. Trata-se, portanto, de discutir e enfrentar ambos os problemas de forma articulada com a luta pela dem ocracia, a justiça social e a sustentabilidade. Assim como não devemos aceitar qualquer desenvo lvim ento econômico ou qualquer em prego a qualquer pre ço, também é neces sá rio evitar pol a rizar ou fragm entar artificialmente a defesa da natu reza, das necessidades dos trabalhadores e das comunidades em geral que habitam os lugares. Para isso é necessário que a noção de sustentabilidade inclua a existência e a qualidade do trabalho, incluindo os indicadores de saúde dos trabalhadores, como um de seus pilares fundamentais.

Essas questões são cen trais diante do atual quadro marcado pela globalização e implem entação da agenda neoliberal, que acen tua o comportamen to indivi dualista e a competição agressiva entre regiões e nações. A diluição das fron tei ras en tre os países e do poder de atuação dos Estados Nacionais têm propiciado a chamada ch a n ta gem locacional, termo de s envo lvido pelo professor da UFRJ, Henri Acselrad, possivelmen te o principal teórico da justiça ambi ental no Brasil. A chantagem locacional significa que o capital negocia seus investim entos nas áreas on de não somente são oferecidas as maiores taxas de lucros, mas as men ores resistências sociais e políticas volt adas ao con trole da po luição e das inju s tiças sociais. Esse é um fator de desmobilização da socied ade que precisa ser enfrentado de forma mais global através da construção de redes sociais e solidárias entre os vários movimen tos sociais, sindicais e ambi entalistas dos vários territórios afetados, sejam eles de um mesmo país, en tre vários países ou continentes. Tais redes possuem como papel pri m ordial o en frentamento de situações de injustiça socioambiental, revertendo as caracterís ticas de proj etos e modelos de de s envo lvimen to insus ten táveis e apoiando iniciativas que levem a modelos mais ju s tos e saudáveis .

Com preen der probl emas de saúde simultaneamen te a partir de perspectivas ecológicas e sociais é fundamental para que propostas de des envo lvimento econômico e tecnológico possam resultar em balanços mais positivos entre os benefícios e os prejuízos dele decorrentes, seja para a saúde dos trabalhadores, da população em geral ou dos ecossistemas. Essa visão nos ajuda a pensar de forma integrada os con cei to $s$ de risco e o de desenvolvimen to econômicotecnológi co a partir da dialética en tre produção-destruição: ao mesmo tempo em que novos processos de produção e tecnologias geram riquezas e con forto, novos ris cos ocupacionais e ambientais podem ser incorporados aos territórios e afetar certos gru pos populaciomis em distintas escalas espaciais e temporais.

Ac reditamos que o campo da Saúde Públ ica/Saúde Coletiva pode desempenhar um importantepapel na construção e fortalecimento do movimento da justiça ambiental no Brasil. Por exemplo, embora probl emas de saúde e saneamen to em sua vinculação com as desigualdades sociais sejam amplamente reconhecidos como fundamentais para serem equacionados pela sociedade brasileira, a agenda do movi$m$ en to ambi entalista bra sil ei ro ainda não pri orizou adequadamen te tais questões, em parte pela assimilação po u co crítica da agenda eco lógica internacional provenien te dos países mais ricos da Europa e América do Norte (Estabrook et al., 2000). A con strução de uma agenda com partilhada en tre os setores da saúde pública e do meio ambiente com diversos movimen tos sociais pode ser de grande valia para o fortalecimento das alianças de stes com diversas instituições e grupos técnicos e acadêmicos, 
eventualmen te dispersos em seus esforços de articulação e intervenção em problemas de nossa realidade.

Acreditamos que o con cei to de justiça ambiental e os movimentos sociais a ele vinculados são estratégi cos para a integração teórica, política e operacional das áreas de saúde do trabalhador e da saúde ambiental. Ao en focar os problemas ambientais - incluindo a saúde dos trabalhadores e os ambi en tes de trabalho comoresultantes de um modelo de desenvo lvimen to econ ô micoe social que con cen tra renda e poder, o tema da justiça ambiental permite pensar de forma integrada o de senvo lvimento de ações de prevenção e promoção da saúde. É através de modelos insustentáveis de desenvolvimento que as comunidades atingidas pelos riscos ocupacionais ou ambientais mais gerais tornam-se vulneráveis em sua capacidade de reconhecer e enfrentar seus problemas socioambientais e sanitários.

Em outras palavras, os riscos decorrentes de processos produtivos e tecnologias que ign oram ou desprezam as necessidades de seres humanos e do meio ambiente não são en frentados somen te por especialistas e cientistas, mas pela atuação organizada dos trabalhadores e dos cidadãos em geral na defesa da vida e da dem ocracia. A com preensão e o en frentam en to das desigualdades é um aspecto central no movim en to pela justiça ambi ental que se coaduna com a história da saúde coletiva e da saúde do trabalhador. A con s trução de alterna tivas futuras de desenvo lvimento econômico e social necessariamente deve passar por processos participativos que defendam formas mais saudávei s autôn omas e sustentáveis no nível local das comunidades, in cluin doos locais de trabalho e as comunidades tradicionais cuja subsistência depende diretamen te da saúde dos ecossistemas on de vivem. Es te último aspecto é vital no fortalecimento da democracia e da consciência ecológica nas sociedades Latino-Americanas, principalmen te qu a n do levamos em consideração a dívida social e cultural relacionada aos povos tradicionais como os indígenas.

Apesar da relevância dos problemas socioambientais, as respostas no campo científi- co con ti nuam res tritas diante da hegem onia da ciência normal e do mundo dos paradigmas isolados dos especialistas, os quais possu em dificuldades intrínsecas de reconhecerem incertezas e ignorâncias. Essa postura limita o desenvo lvi men tode análises integradas e mudanças de paradigmas necessários à con strução de uma ciência da sustentabilidade. Os enfoques ecossistêmicos aplicados aos probl emas de saúde podem con tribuir nessa direção, desde que con textualizads às realidades políticas, econômicas e culturais. Pa ra os países da América Latina, seus probl emas ambi entais e de saúde não podem estar dissociados das ineqüidades socioambientais derivadas do processo de interdependência econômica e ecológica resultante de um mu n do globalizado. Abord a gens ecossociais podem con tribuir na construção de uma ciência para a sustentabilidade, que seja tanto precaucionária qua n to democrática e inclusiva, paut ada em diversos el em en tos, como a noção de complexidade; o reconhecimen to das incertezas; a integração de conhecimentos através de teorias transdisciplinares, metodologias in terdisciplinares e participativas; e a plurali$\mathrm{d}$ ade de interesses e valores legítimos em jogo (Porto, 2004).

A mudança de paradigmas nos campos teóri cos e operacionais engajados na análise e enfrentamento de probl emas de saúde e ambien te também con tri bui para a ren ovação do con ceito de saúde humana, que incorpore, porém tran scenda, a con cepção biomédica, in tegrando-a à saúde das comunidades e dos ecossistemas. Nessa nova perspectiva, a saúde deve ser compreendida simultaneamente a partir das dimensões éticas, sociais, culturais e ecológicas que são irredutíveis para uma visão holística de saúde. A saúde, port a n to, deve ser en ca rada como um concei to dinâmico, multidimensional, qualitativo e evolutivo, envolvendo po tenciais de realização humana em suas esferas fisiológicas, psíquicas e espirituais, sendo objeto de permanente negociação e eventuais conflitos na socied ade, dependendo de como os valores e interesses se rel aci onam nas estrutu ras de poder e distri buição de rec u rsos ex is ten tes (Porto, 2003). 


\section{Referências bibli ográficas}

Acselrad H, Herculano S \& Pádua JA 2004. Justiça ambiental e cidadania. Ed. Relume-Dumará, Rio de Janeiro.

AugustoLGS, Augu s toGSA \& Freitas CM 1998. Oprin cipio da precaução no uso de indicadores de riscos quími cos ambi entais em saúde do trabalhador. Cadernos de Saúde Coletiva 3(2):85-95.

Bullard R 1994. Dumping in Dixie: race, class and environmental quality. Boulder Westview Press.

Conti L 1986. Ecol ogia, capital, trabalho e ambien te. Hucitec, São Paulo.

Corvalán C, Bri ggs D \& Kjell s trom T 1996. Linkagemethods for environment and health analysis: general guidelines. UNEP-EPA-WHO, Document WHO/EHG/95.26, Genebra.

Czeresnia D \& Freitas CM 2003. Promoção da Saúde: reflexões, conceitos, tendências. Fiocruz, Rio de Janeiro.

Est abrook T, Si queira CE, Mach ado EP 2000. Labor- community alliances in petrochemical regions in the United States and Brazil: What does it take to win? Capitalism, Nature, Socialism 11(3):113-145.

Freitas CM 2003. Probl emas ambientais, saúde coletiva e ciências sociais. Ciência \& Saúde Coletiva 8(1):137150.

Fun towicz S \& Ravetz J 1994. Emerging com pl ex sys tems. Futures 26(6):568-582.

Funtowicz S \& Ravetz J 1997. Ciência pós-normal e comunidades ampliadas de pares face aos desafios ambientais. História, Ciências, Saúde - Manguinhos 4(2): 219-230.

Giampietro M 2002. The precautionary principle and ecological hazards of genetically modified organisms. Ambio 31(6):466-470.

Krieger N 2001. Theories for social epidemiology in the 21st cen tury: an ecosocial pers pective. In ternational Journal of Epidemiology 30:668-677.

Kuhn T 1987. A estrutura das revoluções científicas. Ed. Perspectiva, São Paulo.

Leal MC, Sabroza PC, Rodriguez RH \& Buss PM (orgs.) 1992a. Saúde, ambiente e desenvolvimento - uma análi seinterd isciplinar. Hucitec-Abra sco, São Paulo-Rio de Janeiro.

Leal MC, Sabroza PC, Rodriguez RH \& Buss PM (orgs.) 1992b. Saúde, ambiente e desenvolvimen to-processos e conseqüências sobre as condições de vida. HucitecAbrasco, São Paulo-Rio de Janeiro.

Levins R \& Lopez C 1999. Tow a rd an ecosocial vi ew of health. In ternational Journal of Health Services 29(2): 261-293.

Martinez-Alier J 2002. The environmentalism of the poor: a study of e cological conflicts and valuation. Edward Elgar Press, Cheltenham.

M'Gonigle RM 1999. Ecological econ omics andpolitical ecology: towards a necessary synthesis. Ecological Economics 28:11-26.

Min ayo MCS et al. 1999. O programa institucional sobre saúde e ambiente no processo de desenvolvimento da Fundação Oswaldo Cruz. Anais da Academia Brasileira de Ciências 71(2):279-288.
O'Connor M 1994. Is capitalism sustainable? Political Economy and the Politics of Ecology. Guilfort, New York.

Oliva LC 2004. O modelo padrão de análise de riscos em questão e o su rgimento de propostas dem o crático-deliberativas. Dissertação de mestrado. CPDA/UFRRJ, Rio de Janeiro.

Pádua JÁ 2002. Um sopro de destruição:pensamento, politica e crítica ambiental no Brasil escravista - 1786/ 1888. Jorge Zahar Editor, Rio de Janeiro.

Paim JS \& Alm eida Filho N 2000. A crise da saúde pública e a utopia da Saúde Col etiva. Casa da Qualidade Editora, Salvador.

Porto MFS 1998. Saúde, ambi en te e de s envo lvimen to: refl exões sobre a experiência da COPASAD - Con ferência Pan-Americana de Sa ú de e Am bi en te no Contexto do Desenvolvimento Sustentável. Ciência e Saúde Coletiva 3(2):33-46.

Porto MFS \& Al m eida G 2002. Significados e limites das estratégias de integração disciplinar: uma reflexão sobre as contribuições da saúde do trabalhador. Ciência \& Saúde Coletiva 7(2):335-347.

Porto MFS 2004a. Riscos, incertezas e vulnerabilidades: transgênicos e os desafios para a ciência e a governança. Paper apresentado no III Sem iná rio Intern acional de Es tu dos In terdisciplinares "Tecnologias, Ri s cos e Incertezas: Desafios para uma dem ocra tização da ciência”. Un iversidade Federal de SantaCata rina. Florianópolis, 15 a 17 de abril de 2004.

Porto MFS 2004b. Sa ú de Pública e (In)Ju s tiça Ambiental. In H Acs el rad, S Herculano \& JÁ Pádu a. Ju stiça ambiental e cidadania. Ed. Relume-Dumará, Rio de Janeiro.

Porto MFS, L acaz FAC \& Machado JMH 2003. Promoção da saúde e inters etorialidade: con tri buições e limites da vigilância em saúde do trabalhador no sistema único de saúde (SUS). Saúde em Debate 65:192-206.

Possas CA 2001. Social eco s ys tem health: con fron ting the complexity and emergence of infectious diseases. Cadernos de Saúde Pública 17(1):31-41.

Sabroza P \& Waltner-Toews D 2001. Doenças emergentes, s i s temas locais e globalização. Cadernos de Saúde Pública 17(suppl.):4-5.

Strand R 2001. The role of risk assessments in the governance of gen etically modified or ganisms in agriculture. Journal of Hazardous Materials 86:187-204.

Tambellini AT \& Câmara VM 1998. A temática saúde e ambiente no processo de de s envolvimento do campo da saúde coletiva: aspectos históricos, con cei tuais e metodológicos. Ciência e Saúde Coletiva 3(2):47-59.

Teixeira CF, Paim JS \& Vilasboas AL 1998. SUS, m odelos assistenciais e vigilância da saúde. Info rmeEpidemiológico do SUS 7(2):7-28.

Waltner-Towes D 2001. An eco s ys tem approach to health and its applications to tropical and emerging diseases. Cadernos de Saúde Pública 7(Supl.):7-36.

Artigo apres en tado em 16/06/2005

Aprovado em 15/07/2005

Versão final apres entada em 19/07/2005 